University of Nebraska - Lincoln

DigitalCommons@University of Nebraska - Lincoln

Educational Psychology Papers and

Publications

Educational Psychology, Department of

January 1992

Consultation and Teaming: Problem Solving among Educators,

Parents, and Support Personnel

Stephen N. Elliott

University of Wisconsin-Madison

Susan M. Sheridan

University of Nebraska-Lincoln, ssheridan2@unl.edu

Follow this and additional works at: https://digitalcommons.unl.edu/edpsychpapers

Part of the Educational Psychology Commons

Elliott, Stephen N. and Sheridan, Susan M., "Consultation and Teaming: Problem Solving among Educators, Parents, and Support Personnel" (1992). Educational Psychology Papers and Publications. 1. https://digitalcommons.unl.edu/edpsychpapers/1

This Article is brought to you for free and open access by the Educational Psychology, Department of at DigitalCommons@University of Nebraska - Lincoln. It has been accepted for inclusion in Educational Psychology Papers and Publications by an authorized administrator of DigitalCommons@University of Nebraska - Lincoln. 


\section{Consultation and Teaming: Problem Solving among Educators, Parents, and Support Personnel}

\section{Stephen N. Elliott}

University of Wisconsin-Madison

\section{Susan M. Sheridan}

University of Utah
This article examines the nature and use of consultation and in-school teams in the delivery of psychoeducational services for children experiencing difficulties in school. Underlying both consultation and school-based teams is an explicit problem-solving process that has been shown to facilitate problem resolution for a target child and can also advance the knowledge of the adults who participate in the process. Practical, step-by-step illustrations of problem solving within a consultative relationship are provided and extended to team problem solving. Research literature supporting these practices also is briefly reviewed.

Educational and psychological services for handicapped children in U.S. schools are contingent on communications, decisions, and actions of adults-typically regular educators, special educators, parents, and specialists such as psychologists, speech pathologists, or physical therapists. Communications and decisions concerning handicapped children focus on the identification and analysis of the child's problem(s); methods for resolving the problem(s); resources, personnel, and setting for solving the problem(s); criteria for deciding when a problem is resolved; and legal/ethical aspects (e.g., due process, prior consent, nonbiased assessments) that guide decision making. Many of these communications occur within consultative relationships between dyads (e.g., special educator/regular educator, psychologist/regular educator, psychologist/parent) and periodically within larger groups, often referred to as multidisciplinary staffings or conferencing teams.

The purpose of this article is to examine the nature and use of consultation and 
school-based teams in the effective delivery of services for mainstreamed handicapped children. Much has been written about consultation during the past decade and has been discussed in detail in books such as those by Bergan and Kratochwill (1990), Conoley and Conoley (1982), and Idol, Paolucci-Whitcomb, and Nevin (1986). The art and science of multidisciplinary teams have received less attention; nevertheless, several chapter-length treatments do exist (e.g., Huebner \& Hahn, 1990; Maher \& Yoshida, 1985; Pfeiffer \& Hefferman, 1984). In this article we summarize some of the knowledge on consultation and multidisciplinary conferences and provide readers with practical suggestions for enhancing communication and cooperation on behalf of children.

\section{Consultation: Basic Considerations}

With the current interest in educational reform and restructuring (Carnegie Task Force on Teaching as a Profession, 1986; Holmes Group, 1986; National Commission on Excellence in Education, 1983), many educators advocate alternative methods of addressing the needs of all students (Friend \& Cook, 1990; Nevin, Thousand, Paolucci-Whitcomb, \& Villa, 1990; Phillips \& McCullough, 1990; Zins, Curtis, Graden, \& Ponti, 1988). It is currently recognized across disciplines that there are growing numbers of students requiring alternative assistance (American Association of School Administrators, 1988; Saxe, Cross, \& Silverman, 1988) and that current models of service delivery are ineffectively meeting the needs of these children and adolescents (Knitzer, 1982). Consultation and other forms of collaborative problem solving across disciplines have been espoused by many as the foundations for a range of alternative services designed to enhance general educational experiences (Cole \& Siegel, 1990; Curtis \& Meyers, 1988; Idol et al., 1986; Phillips \& McCullough, 1990). Such service delivery options promote enhanced professional relationships and shared re- sponsibility in planning, decision making, and problem solving.

Idol and West (1987) identified 10 models or approaches to consultation; therefore, there is not one accepted definition of consultation. In general, these varying models of consultation have much more in common than is different and lead us to define consultation as a method for providing psychological and educational services to children by forming a cooperative, problem-solving relationship whereby consultants share knowledge with consultees who in turn work directly with a client to change his/her functioning. The most definitive characteristic of this definition and the practice of consultation is the indirect service concept. The concept of indirect service delivery rests on the assumption that teachers and parents generally are the "best" people to work with children; however, the knowledge and skills of other professional specialists are often needed to develop effective change strategies. Figure 1 illustrates the indirect nature of consultative services and compares this model to direct or traditional means of delivering services to children.

Along with the indirect focus of consultation, other common characteristics have been identified across models. These include the notions of coordinate status, coownership of problems and problem solving, shared participation, recognition of consultee rights, voluntariness, mutual goals, and shared resources (Friend \& Cook, 1990; Gutkin \& Curtis, 1990). Traditionally, school-based consultation has occurred with specialists (e.g., school psychologists) serving as consultants and teachers serving as consultees. However, the consultee role could be broadened to include parents, administrators, paraprofessionals, or other individuals. Furthermore, the nature of the consultee role could be expanded to include a "consultee subsystem," whereby a group of consultees (e.g., parents and teachers) is enjoined to work collaboratively for the benefit of the child. This collaboration may increase generalization of treatment effects 
TRADIMONAL SERVICE MODEL

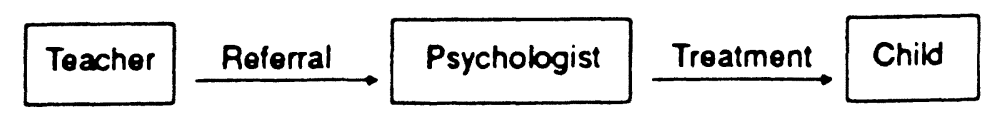

CONSULTATION MODEL

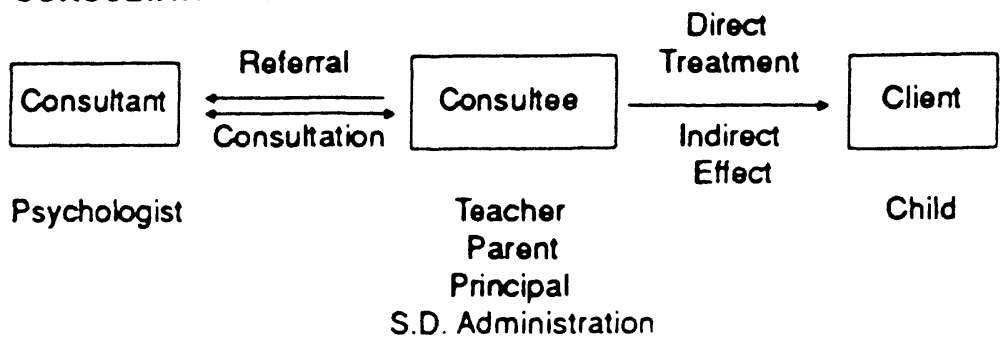

Fic. 1.-Traditional and consultation service models. Source.-Anserello and Sweet (1990). Reproduced with the permission of Hogrefe \& Huber Publishers, 12 Bruce Park Avenue, Toronto, Ontario, Canada M4P 2S3, from Effective Consultation in School Psychology, edited by E. Cole and J. Siegel (1990). Copyright (C) 1990 by Hogrefe \& Huber Publishers. Adapted from "School-based consultation: Theory and Techniques," by T. B. Gutkin and M. J. Curtis (1982). In C. R. Reynolds and T. B. Gutkin (Eds.), The Handbook of School Psychology. New York: John Wiley and Sons, 1982. Copyright (C) 1982 by John Wiley \& Sons, Inc. Reprinted by permission of John Wiley \& Sons, Inc.

across settings or behaviors and enhance relationships among significant individuals in a child's life (Sheridan, Kratochwill, \& Elliott, 1990).

In the remainder of this article, we discuss characteristics of and research most consistent with a behavioral model of consultation. This model is perhaps the most widely used in schools, given that much of the seminal work in school-based consultation has been done by Bergan (1977; Bergan \& Kratochwill, 1990; Kratochwill \& Bergan, 1990). Readers interested in the theoretical underpinnings and practical issues in implementing mental health consultation in schools are referred to the work of Meyers, Parsons, and Martin (1979). Those interested in organizational development are referred to Schmuck (1990) and Schmuck and Runkel (1972).

Behavioral consultation has two important goals: (a) to provide methods for changing a child's learning or behavior problem, and $(b)$ to improve a consultee's skills so he/she can prevent or respond more effectively to future or similar problems in other children. Many published ac- counts document the effectiveness of behavioral consultation in attaining its first goal; however, its preventative utility has not been adequately documented. Before examining the research literature on consultation, a more detailed analysis of the structure and process of behavioral consultation is in order. Be aware that much about the structure and process of consultation is also relevant to conducting a variety of effective interdisciplinary teams, a topic we discuss in the second half of this article.

\section{The Structure and Process of}

\section{Consultation}

Of all the approaches to consultation, behavioral consultation appears to have the most defined structure for facilitating problem solving. Specifically, behavioral consultation has been defined as a series of stages that direct and focus the problemsolving inquiries between a consultant and a consultee. Bergan (1977) developed a four-stage heuristic framework for guiding the consultative process. These stages are labeled problem identification, problem analysis, plan implementation, and plan 
evaluation. Each of these stages will be described briefly.

Problem identification. This stage is the initial and, according to many researchers, the most critical stage of consultation. During this interview stage, the consultant and consultee describe and operationally define the child's behaviors that are of concern to the parent or teacher. In behavioral consultation a "problem" is a relative concept that is operationalized when the parent or teacher reports a significant discrepancy between the child's current level of functioning and the desired level of performance. This approach to problem identification is based on the assumption that problems are the result of unsuccessful or discrepant interactions between persons. Thus, the consultant and the consultee(s) (e.g., parents, teacher) first analyze the target problem within the context of the child and his/her interactions with the environment. When baseline data support the existence of the specific problem behavior, the consultant and consultee begin to jointly identify variables that might lead to behavior change and problem resolution.

Problem analysis. This second stage of behavioral consultation focuses on variables and conditions that are thought to influence the child's behavior. Problem analysis is a natural extension of the problem identification stage; that is, it begins with the targeted behavior and focuses on establishing functional relationships between it and the antecedent or consequent events. Relevant questions posed during this stage are concerned with who, what, where, when, and under what conditions the problem occurs. In many cases, consultants and consultees will need to collect additional information about the child and his/her situation before the major questions of this stage can be answered. Problem analysis often enhances, refines, and, consequently, redefines the target problem and the variables that influence it.

Although child behaviors are often the focus of intervention, this does not suggest that the source of the problem is internal to the child or that the child must be the sole recipient of treatment. Indeed, consultees' perceptions, skills, or attitudes, the classroom setting, or instructional variables may contribute to an incongruent relationship between the child and the academic environment. These factors should be analyzed during problem analysis and may warrant consultation attention (Zins \& Ponti, 1990).

Plan implementation. This stage follows the problem analysis stage and focuses on the selection of an appropriate intervention and its implementation. The selection of interventions traditionally seems to have been based on the reported or assumed effectiveness of a particular method. Many consumers and providers of psychological services, however, are demanding that interventions also be acceptable. Elliott (1988) has found that factors such as time efficiency, degree of restrictiveness, degree of risk to the child, side effects on other children, and general fairness all may influence teachers' reactions and use of classroom interventions. Likewise, interventions that are consistent with a teacher's and parent's child management philosophy and compatible with existing resources and skills of the individual delivering the intervention also have gained recent consumer interest and empirical support (Witt \& Martens, 1988). Thus, the design and selection of appropriate interventions during behavioral consultation are based on behavioral principles of human functioning and require attention to issues of intervention acceptability and effectiveness and consultee skills and resources. Plan implementation also involves discussing and actually carrying out the selected intervention. This substage may consume several weeks and is characterized by interactions between the parent or teacher and child. These interactions often occur through brief contacts in which the consultant monitors intervention integrity and side effects and discusses with the consultee ways to revise the plan and its use. 
Plan evaluation. This is the final stage of consultation. Its objectives concern the establishment of an empirical basis for interpreting outcomes of the intervention and the provision of a forum for evaluating plan effectiveness. Single-subject or case-study designs using direct observations of the target behavior provide the primary means for evaluating change in the child's behavior. In theory, a consultative case is not concluded until the discrepancy between the child's existing and desired behavior is reduced substantially and the plan is acceptable. Therefore, it is often necessary to go back through previous stages of consultation and to reevaluate and refine newly implemented interventions.

In summary, behavioral consultation provides a framework for guiding the conceptualization of a problem and a means for planning a solution for resolving the problem. Although the problem-solving structure presented here is sequential and overt, it should not be interpreted as inflexible or irreversible. The activities of consultants and consultees are multifaceted and involve at least interviews, observational assessments of a child, treatment of a target behavior, and evaluation of the treatment. Such a range of activities often involves serveral interactive, collaborative sessions between the consultant and consultee. We now examine some of the research that supports the consultative enterprise.

Research on the Use and Effectiveness of Consultation

During the past decade at least eight reviews have been published examining the efficacy, processes, and use of school-based consultation (Alpert \& Trachtman, 1980; Alpert \& Yammer, 1983; Bergan, 1977; Gutkin \& Curtis, 1982; Medway, 1979, 1982; Meyers et al., 1979; Updyke, Melton, \& Medway, 1981), and a miniseries focusing on indirect services in schools was featured in School Psychology Review (Conoley, 1986, vol. 15, no. 4). As Gresham (1984) noted, reviewers largely have agreed concerning what we know empirically about consultation in schools. This research can be organized around three areas of investigation: (a) outcome research, $(b)$ process research, and $(c)$ practitioner training and utilization. In the following subsections, we briefly highlight research findings in each of these areas.

Consultation outcome research. Dependent or outcome measures in school consultation research typically have included changes in consultees' classroom behavior; changes in consultees' knowledge, perceptions, and attitudes; changes in clients' classroom behavior; and changes in the frequency of using consultation. At this time, in comparison to other approaches to consultation, the greatest empirical support exists for behavioral consultation (Gresham \& Kendell, 1987; Medway, 1979), and more than $75 \%$ of research focuses on behavioral consultation methods (Alpert \& Yammer, 1983). Unfortunately, few consultation researchers have done long-term follow-ups to assess the maintenance of behavior changes in consultees or clients. With regard to outcomes of consultation, the following findings seem robust.

1. Teachers exposed to consultation services believe that their professional skills have improved (e.g., Gutkin, 1980). Moreover, teachers who have been involved with consultation report problems to be less serious than teachers in matched schools who have experienced similar problems but have not been exposed to consultants (Gutkin, Singer, \& Brown, 1980).

2. Referral rates for special educational services drop significantly after 4 or 5 years of exposure to consultation services (e.g., Gutkin, Henning-Stout, \& Piersel, 1988; Ritter, 1978).

3. Underachieving children whose teachers and parents receive consultation services during fourth, fifth, and sixth grades performed significantly better on several academic measures at the time of school graduation than a matched control group of underachievers (e.g., Jackson, 
Cleveland, \& Merenda, 1975). Similar findings have been documented with children characterized as socially withdrawn and whose teachers and parents jointly participated in consultation (Sheridan et al., 1990).

Consultation process research. As outlined earlier in this article, the consultation process involves several stages and places a premium on communication between two or more individuals. Given these features, literally hundreds of variables could influence the consultation process. Some of the major findings regarding the process of consultation follow.

1. The single most important process variable in consultation is problem identification. Thus, the best predictor of plan implementation and problem resolution is a consultant's ability to work with the consultee to define problems in behavioral terms (Bergan \& Tombari, 1975, 1976; Fuchs \& Fuchs, 1989).

2. Teachers are more likely to identify resources they can use in carrying out an intervention plan if the consultant asks rather than tells them how they can identify and use resources (Witt \& Martens, 1988). For example, according to Bergan and Neumann (1980), the chances are 14 times greater that a teacher will identify resources and a procedure to carry out a consultation plan if the consultant asks rather than tells the teacher.

3. Consultees' perceptions of consultants' communication skills affect the overall effectiveness of consultation as judged by teachers. Specifically, genuineness, empathy, active listening, and paraphrasing are perceived by consultees as indicative of good communication skills (Gutkin, 1986; Gutkin \& Curtis, 1982).

4. Teachers dislike the use of jargon by consultants and prefer "common-sense" language in the description of consultation plans (Witt, Moe, Gutkin, \& Andrews, 1984).

5. Consultees who believe that a client's behavior problem results from internal or home factors are more resistant to consul- tation than those consultees who believe a client's behavior is due to external factors (Gutkin, 1986; Gutkin \& Bossard, 1984).

6. The amount of teacher time required, the severity of the client's behavior problem, and the type of intervention are all salient dimensions to consider in evaluating teachers' acceptability of consultation plans (Elliott, 1988; Witt \& Elliott, 1985).

7. Behavioral interviews, as part of consultation, have a reasonable degree of psychometric adequacy in terms of interrater reliability, content validity, and criterion-related validity (Gresham, 1984).

Use of consultation. School consultation frequently is promoted as one of the most preferred job functions of school psychologists and special educators (Fuchs \& Fuchs, 1989; Gutkin \& Curtis, 1982, 1990). According to Curtis and Zins's (1988) research, teachers and administrators also view consultation as one of the most important aspects of special services from psychologists and special educators. Unfortunately, many potential consultants state that they do not have enough time to do consultation because of the diagnostic role requirements imposed on them by special education (Alpert \& Trachtman, 1980). Understanding the time and service demands of a system increases the likelihood that consultation will be used. Happe's (1982) research provides some insights into why consultees often do not try consultation. Specifically, he found that the three most frequent reasons consultees gave for not attempting a consultation plan were (a) "I don't have time," (b) "I can't do that for just one child," and (c) "It's not fair to do that for just one child." Happe (1982) also investigated how school psychologists were able to increase the likelihood of teacher or parent commitment to try a consultation plan. The three ways that seem the most effective were making sure the consultee's ideas for solving the problem are incorporated into the consultation plan, providing explicit instructions for carrying out the 
plan, and telling the teacher or parent that you have seen the plan work successfully.

As indicated by this brief reveiw of consultation research, we are only beginning to understand fully the process and efficacy of consultation. Many basic questions about the acceptability, use, and effectiveness of consultation remain to be answered, and significant advances in research design and methodology have been outlined to facilitate deriving meaningful answers (Gresham \& Kendell, 1987). Presently, it seems safe to say that behavioral consultation is an important and often preferred method for providing services to at-risk and handicapped children. As we have indicated, there is some empirical support for the practice of behavioral consultation. This practice draws on knowledge of communication dynamics, intervention design and treatment techniques, and an understanding of educational system variables that influence consultees' available time and motivation.

\section{Implementing Behavioral Consultation}

As discussed earlier, consultation, and in particular behavioral consultation, can be conceptualized as a problem-solving endeavor consisting of four stages that focus on problem identification, problem analysis, plan implementation, and plan evaluation. Best practices in consultation suggest that specific interview objectives should be accomplished within every stage and that issues of treatment acceptability, treatment integrity, and treatment effectiveness be monitored throughout the consultative interaction. The major components of each of the four stages of behavioral consultation are outlined next.

\section{Problem Identification}

The problem identification stage of consultation typically involves generating precise descriptions of a student's behavior, carefully analyzing the conditions under which the target problem(s) occur, and establishing some indication of the level of persistence or severity of the problem(s). Another important objective in this stage is establishing an assessment technique. Together, the consultee and consultant should agree on the type and kind of measure to be used, what will be recorded, and how this assessment process will be implemented. Finally, several procedural objectives involving establishing times, dates, and formats for subsequent interviews to analyze the problem with the consultee need to be completed. Witt and Elliott (1983) outlined nine components that facilitate a successful problem identification interview. These components are written as objectives and briefly are described as follows.

1. Explanation of problem definition purposes. The consultee should be told what is to be accomplished during the interview and why problem identification is important. (Example statement: "I would like to talk with you a few minutes about Jim and his behaviors that bother you most. We will need to assess his behaviors, when and how they occur, and what factors in your classroom influence them.")

2. Identification and selection of target behaviors. The consultee should be asked to focus on the problematic aspects of a student's difficulties. (Example statement: "Please describe exactly what Jim is doing that has caused you concern.") When individuals identify multiple problems, it is necessary to determine which to address first. (Example statement: "Which of these concerns about Jim is most pressing to you now?")

3. Identification of problem frequency, duration, and intensity. After a target behavior has been defined, it is helpful to assess its basic characteristics: How often it occurs (frequency), how long it lasts (duration), and how strong it is (intensity). (Example statements: "How many times did Jim cry last week? How long does each crying session last? Does he cry loudly enough for everyone in the room to hear him?") To interpret descriptions of fre- 
quency, duration, and intensity, the consultee may be asked to compare the target child's behavior with that of other children. In addition, a consultant should have knowledge of normative expectations to which the child's behavior can be compared.

4. Identification of the conditions under which the target behavior occurs. The assessment of environmental factors that occur in conjunction with a target behavior is essential in understanding the problem. (Example statement: "How do you and the class react to Jim's crying?") Use of a simple model of behavior, such as the ABC model, can help clarify many problems. This model characterizes behavior (B) as a function of antecedent (A) and/or consequent (C) events. Thus, once a behavior has been identified, examination of events that precede and follow it becomes informative about what in the environment may be influencing the problem behavior.

5. Identification of the required level of performance. Obtaining a description of the behavior required of a student is as important as obtaining a description of the student's problem behavior. (Example statement: "What would you consider to be an acceptable frequency for this out-of-seat behavior?") Once a desired or expected level of performance is identified, it serves as an ultimate goal. Note that subordinate goals and objectives may also be identified, goals that would be achieved en route to attainment of the larger goal. For example, careful task analysis can determine prerequisite skills required prior to achievement of the ultimate target behavior.

6. Identification of the student's strengths. Learning what a child does well is often more useful than learning what a child does not do or does poorly. (Example statement: "What does Jim do best when interacting with his classmates?") Developing interventions that use a student's strengths helps to increase the probability of a successful treatment.

\section{Identification of behavioral assess-} ment procedures. All interventions require some assessment or recording of behavior. Thus, a consultant should help a consultee to decide what, how, when, and where behavior will be recorded and the person responsible for the recording.

8. Identification of consultee effectiveness. Given that one major goal of consultation is to enable a consultee to solve similar student problems when confronted with them in the future, it often is necessary to teach or model problem-solving skills and enhance the consultee's confidence in his/ her ability to solve problems. To accomplish this, Witt and Martens (1988) advocate an empowerment, rather than an advice-giving, philosophy of service for consultants. An empowerment philosophy assumes that consultees basically are skilled individuals who can become more capable of solving their own problems by knowing what resources are available and how to gain access to them (Dunst \& Trivette, 1988). One can determine the consultee's potential effectiveness by asking about how similar problems have been handled in the past, assessing what methods the consultee already has used to remediate the target problem, and judging whether the consultee is selfreliant or dependent on others for reinforcement (Meyers, Liddell, \& Lyons, 1977).

9. Summary of the interview. The final step in the problem identification stage should include a summary of the important points discussed and a review of the problem definition. This summary should include a statement of the specific target behavior(s) or clarification of any further assessment necessary to refine the target behavior(s).

\section{Problem Analysis}

After baseline data are collected on the target behavior, the consultant and consultee meet to decide jointly on factors that might lead to some resolution of the problem. In this regard, the consultation process focuses on student, consultee, and general 
environmental variables that may be of relevance.

The problem analysis interview includes four major steps or objectives: (a) choosing analysis procedures, $(b)$ conducting a conditions and/or skills analysis, (c) developing treatment strategies, and $(d)$ establishing procedures to evaluate performance during implementation of any treatment program. According to Kratochwill, Elliott, and Rotto (1990), the consultant and consultee must specify the goals of the treatment (i.e., increase a behavior, decrease a behavior, and/or maintain a behavior) and focus on conditions that facilitate attainment of the mutually agreed-on goals. Through mutual problem-solving efforts, the consultantconsultee team must analyze the specific child skills necessary to achieve the treatment goals during this stage of consultation. The outcome of a successful problem analysis interview is a plan that will be put into effect during the treatment implementation process.

Many consultants and consultees report this to be the most difficult stage to complete. It has a dual focus, first, on the child's behavior, and, second, on treatment methods that are likely to change the child's behavior. These methods almost always affect the consultee's behavior. Witt and Martens (1988) have cautioned consultants to consider the skills and resources of consultees to guard against creating a bigger problem for consultees. That is, interventions that are new to consultees and require significant time and some new behaviors will likely become problematic for consultees, thus the interventions may not be implemented. Skillful consultants work cooperatively with consultees to ensure that they already have the skills (or can quickly acquire them) and resources to carry out an intervention. Elliott and Gresham (1989) have developed a set of rating scales, referred to as the Prereferral Behavior Inventory and Intervention Planner (PBIIP), designed to facilitate a clearer understanding of teachers' skills and child-management preferences. Appendices A and B include sections from the PBIIP concerning teachers' self-reports of their effective teaching behaviors and intervention preferences. These scales are used most effectively prior to or in conjunction with a problem analysis intervention. A similar set of scales has been developed for parent consultees with a particular focus on homework and child management.

\section{Plan Implementation}

An effective analysis of a child's problem behavior should lead to the development of a plan to resolve the problem. In effect, the consultant and consultee are confronted with the questions, What can be done to change the child's behavior? Of the possible procedures, which is most acceptable? Which is likely to be effective? This stage of consultation demands that a consultant have command of a variety of effective treatment methods that are practical for and acceptable to consultees. Selecting, recommending, and ensuring that such treatments are successfully implemented often are challenging. The selection of a treatment for a given problem is influenced not only by the client's particular problem but also by characteristics of the consultee (e.g., philosophy about using reinforcement or punishment techniques, knowledge and skills necessary for implementing a technique, attitude about treating one child differently from others) and the environment (e.g., number of other children, physical layout of room) in which the treatment is to be implemented. Thus, a consultee's active participation in developing specific plan strategies is critical.

Many of the selection and implementation variables we discussed recently have been investigated under the rubic of treatment acceptability (Elliott, 1988; Witt \& Elliott, 1985). Kazdin (1981, p. 473) defined treatment acceptability as "judgments by laypersons, clients, and others of whether treatment procedures are appropriate, fair, and reasonable for the problem or client." 
Issues of selection and use of treatments are magnified when a person works in a consultative or indirect service arrangement whereby a consultee actually carries out the treatment with the target child. A review of the treatment acceptability and use research is beyond the scope of this article; however, a copy of one of the most frequently used rating scales for assessing the acceptability and perceived effectiveness, the Behavior Intervention Rating Scale (BIRS) (Von Brock \& Elliott, 1985), is presented in Appendix C. This scale is designed for use with teachers, and its content reflects four of the major concerns of teachers in regard to schoolbased treatments. Specifically, teachers want treatments to be time efficient, have no negative side effects on nontarget children, have no risk of harming the target child, and be fair and reasonable. The BIRS can be used formally or informally to guide contacts with consultees during the planimplementation stage.

Once a plan or treatment has been selected, the next major task in this stage is to ensure that the consultee actually has the skills and resources to carry out the treatment. A variety of approaches have been used to ensure the consultee possesses the requisite skills and resources. With teachers these efforts range from providing verbal or written instructions to actually modeling for and coaching teachers in the delivery of the treatment. When parents are the consultees, similar methods can be used; however, it is more likely that a series of parent training sessions will be required whereby basic management skills are taught and reviewed along with specific intervention methods (e.g., differential reinforcement, timeout).

After the treatment has been selected and implemented, it is important for the consultant to meet with the consultee to review how the treatment is progressing. It is best if this review is data based. If little progress is evident, then refinement of the treatment should be considered by reverting to either the problem analysis stage or the early part of the plan implementation stage.

\section{Plan Evaluation}

A plan is evaluated through a formal interview typically conducted to determine whether the goals of consultation have been accomplished. The process of a plan evaluation includes assessment of goal attainment, plan effectiveness, and implementation planning. The first and most important step in plan evaluation is to decide whether or not the actual goals for the child that were previously agreed on have been attained. This decision is determined through discussion with the consultee and observation of the client's behavior. Determination of the congruence between behavior and objectives generally leads the consultant to conclude that no progress was made, some progress was made, or the actual goal was obtained. The effectiveness of the treatment for the client can be determined in several ways. If a quantifiable standard of behavior has been used to define the problem, then comparison of the client's behavior during the treatment to the standard should provide useful evidence for or against treatment effectiveness. Comparison of the target child's behavior after treatment to that of children already exhibiting the desired behavior (i.e., peer comparisons) is a pragmatic and socially valid method of measuring outcome effectiveness. Feedback from significant adults (e.g., parents, other teachers, principal) about their perceptions of the child's behavior after treatment, although generally less quantitative, provides another socially valid method of determining the outcome(s) of treatment.

Once it has been determined that the client's problem has been solved, posttreatment planning should occur to help reduce the likelihood of the problem reoccurring. This phase of consultation generally is referred to as planning for maintenance and generalization. Significant evidence exists that specific plans are needed to facilitate 
maintenance and generalization of behavior and that this must be accomplished during the consultative process (Haring, 1988).

It is evident that successful consultation is a problem-solving process that involves a wide range of assessment and intervention activities, a sensitivity to the consultee's skills and environmental constraints, and a commitment to following a case for a significant period in order to know if treatments are effective or in need of refinement. Consultative interactions with parents or teachers are rarely one-time interactions. Instead, these interactions often consume several hours and occur over several weeks. The dividends for consultation are in changing both a client's and a consultee's behavior.

In the final segment of this article we examine conferencing and school-based teams in the context of educational problem solving for handicapped children. The problem-solving process outlined for consultation (i.e., problem identification, problem analysis, plan implementation, and plan evaluation) also applies to the successful functioning of multidisciplinary teams, although the number of people often involved in such meetings of the latter is two or three times that involved in traditional consultation.

\section{Multidisciplinary Conferencing}

Since the enactment of Public Law (P.L.) 94-142 and its corollary mandates from state departments of education, all students with special needs must be identified and served appropriately. Thus, educational decision-making teams composed of teachers, parents, and support personnel have been required to ensure that such a mandate is carried out. These multidisciplinary teams have been referred to as child study teams, assessment teams, evaluation and placement committees, and school appraisal teams. The implicit rationale for a team approach to educational decision making is based on the belief that a group decision provides safeguards against individual errors in judgment while enhancing adherence to due process requirements (Pfeiffer, 1980).

The team approach to assessment and decision making has been used by mental health professionals for many years (Black, 1977). As a result, a number of writers advocated applying the team concept in the public schools. According to Pfeiffer (1981), "The key elements of a multidisciplinary team are a common purpose, cooperative problem solving by different professionals who possess unique skills and orientations, and a coordination of activities" (p. 330). Given these elements, multidisciplinary teams have been expected to provide a number of functional benefits beyond those provided by any single individual. These benefits include greater accuracy in assessment, classification, and placement decisions; a forum for sharing differing views; provision for specialized consultative services to school personnel, parents, and community agencies; and the resources for developing and evaluating individualized educational programs for exceptional students (Pfeiffer, 1981; Yoshida, 1980; Ysseldyke, Algozzine, \& Thurlow, 1980).

The manner in which multidisciplinary teams have operated varies across states, districts, and schools. Historically, the primary goals of these teams were to $(a)$ determine the student's eligibility for special education, $(b)$ determine whether sufficient types of information about the student are available to the placement team before making decisions affecting the student's instructional program, $(c)$ evaluate the educational significance of such data, $(d)$ determine student placement, $(e)$ formulate appropriate year long educational goals and objectives for the student, $(f)$ develop specific short-term instructional objectives for the student, $(g)$ communicate with parents about changes in the student's educational program, $(h)$ plan information needed for future review of the student's program and 
progress, $(i)$ establish the specific date for placement team review, $(j)$ review the continued appropriateness of the student's educational program, and $(k)$ review the student's educational progress (Fenton, Yoshida, Maxwell, \& Kaufman, 1979).

The Fenton et al. (1979) framework was developed early in the existence of P.L. 94142. Hence, the model appears to espouse and promote primarily a referral function of multidisciplinary teams. This philosophy has received subsequent criticism by educational researchers and practitioners, who have argued that the traditional special education referral process is unreliable, inefficient, and results in an overidentification of children in special education (Algozzine \& Ysseldyke, 1981; Christenson, Ysseldyke, \& Algozzine, 1982; Graden, Casey, \& Christenson, 1985). Alternatively, teams may function more effectively and proactively if they consider process goals along with other problem-solving and decision-making goals. Examples of process goals follow.

1. Ask different questions about children. Focus on "What can be done to help the child?" not "What is wrong with the child?"

2. Be realistic about setting goals. Determine what is both acceptable and possible for educators, parents, and children.

3. Understand the needs and attitudes of individual educators and systemwide factors affecting the team's functioning and decisions.

4. Consider alternative methods of responding to children's needs, including preventative programs, classroom-based interventions, and so on.

5. Evaluate team functioning. Conduct formative evaluations of team functions to determine effectiveness at child, classroom, and system levels (Siegel \& Cole, 1990a).

It is largely agreed that the perceived benefits of multidisciplinary teams have not come to fruition consistently. No single fac- tor can account for the apparent malfunctions of teams; rather, it is hypothesized that an array of intra- and interindividual characteristics of team members combined with the personal and procedural dynamics of a team have resulted occasionally in these malfunctions. Several writers have criticized the team concept. Hefferin and Katz (1971) suggested that teams frequently generate ambiguous decisions, while Wallace (1976) argued that teams raise concerns about professional territoriality.

An Overview of Research on

Multidisciplinary Teams

A search of the literature resulted in 20 articles on multidisciplinary teams. Four of these articles were reviews, and 16 were data-based investigations of the functioning of multidisciplinary teams. The majority of the data-based articles were reports of surveys concerning the actual or the perceived practices and attitudes of multidisciplinary team members (Armer \& Thomas, 1978; Fenton et al., 1979; Poland, Ysseldyke, Thurlow, \& Mirkin, 1979; Smith \& Knoff, 1981; Ysseldyke, Algozzine, \& Thurlow, 1980; Ysseldyke, Regan, \& Schwartz, 1980). Three data-based articles reported direct observational studies of multidisciplinary teams in action (Applied Management Sciences, 1979; Goldstein, Strickland, Turnbull, \& Curry, 1980; Ysseldyke, Algozzine, \& Thurlow, 1980). These observational studies focused primarily on group communications and dynamics and goal-related issues. The four review articles were concerned primarily with functional issues of multidisciplinary teams (Butler \& Maher, 1981; Pfeiffer, 1980, 1981; Yoshida, 1980).

Studies on the accuracy of multidisciplinary teams' decisions have yielded equivocal results. Although there is some tentative support for the notion that placement decisions made by teams are more reliable than those made by individuals (Pfeiffer \& Naglieri, 1983), no information is available regarding other decisions made by teams (e.g., diagnostic or prognostic decisions, selection of behavioral objectives or 
interventions) (Huebner \& Hahn, 1990). Furthermore, many problems with multidisciplinary team processes have been identified. For example, input from various disciplines is disproportionate, with assessment personnel (e.g., school psychologists and special educators) contributing the most, and regular education teachers and parents contributing very little. Relatedly, the majority of time in multidisciplinary team meetings is spent on diagnostic decision making, with much less time spent on the selection and development of interventions (Ysseldyke, 1983).

Pfeiffer and his associates (1980, 1981; Pfeiffer \& Hefferman, 1984) categorized the various problems commonly experienced in multidisciplinary teams. His analyses resulted in four categories of problems: (a) teams' unsystematic approach to collecting and analyzing diagnostic information, $(b)$ the minimal involvement of parents and regular educators on teams, $(c)$ teams' use of a loosely constructed decision-makingplanning process, and $(d)$ the lack of interdisciplinary collaboration and trust (Pfeiffer, 1981). Pfeiffer's analysis of problems experienced by teams was based on research that has focused on a limited number of factors that can be hypothesized to affect the performance of multidisciplinary teams.

The research on the functioning of multidisciplinary teams has not provided a data base for determining what is the "best" or most effective procedure to follow to enhance the probability of making high-quality decisions. We believe, however, that the consultation literature on problem solving has much to offer individuals wishing to run effective school-based teams or parent conferences. We now turn to this literature and apply it to school team meetings.

\section{Consultation's Contribution to Team Meetings}

In the first half of this article we described consultation, in particular, behavioral consultation as conceptualized by Bergan (1977), and reviewed research and best practices with consultation. Gutkin and Curtis $(1982,1990)$ proposed a modified version of the basic behavioral model of consultation that appears to be more directly applicable to the practices of most interdisciplinary teams. The Gutkin and Curtis model of consultation has seven stages: (a) define and clarify the problem, $(b)$ analyze the forces impinging on the problem, (c) brainstorm alternative interventions, $(d)$ evaluate and choose among alternative interventions, $(e)$ specify consultee and consultant responsibilities, $(f)$ implement the chosen intervention, and $(g)$ evaluate the effectiveness of the intervention and go through previous stages if necessary. The major difference between the Gutkin and Curtis model and the Bergan model is that the former explicitly emphasizes brainstorming and choosing alternative intervention strategies. Problem solving, as defined by either model, is intended to maximize the probability that people will generate the best available solution when faced with a presenting problem.

An analysis of the difficulties experienced by school-based teams suggests that their central problem is a lack of a systematic plan for collecting and using assessment data. Therefore, the application of a problem-solving consultative model like that developed by Gutkin and Curtis (1982) could result in a significant improvement in the effectiveness of the teams' meetings.

Problem-solving guidelines for conferencing. Elliott (1986) developed problemsolving guidelines for use by teams of educators and parents to facilitate meetings. These guidelines were based on the Gutkin and Curtis model of consultation. A brief examination of each of the eight steps of this model (see App. D) can serve as a blueprint for working through a problem-solving meeting that involves a collection of professionals and parents. Futhermore, the guidelines can be supplemented with a series of questions related to program planning and evaluation, as suggested by Siegel and Cole (1990a) (see App. E). 
Step 1: Define and clarify the presenting problem. Although most untrained problem solvers believe the construction of an appropriate definition of a problem is a relatively easy task, researchers and experience have proven them wrong. To complete this portion of the process successfully, the team or group must state the presenting problem in concrete, explicit terms. It is crucial to avoid vagueness and ambiguity. The team should also discuss appropriate goals for each relevant aspect of the child's problem(s).

Step 2: Analyze the context of the problem. During this phase of problem solving, the team members' goal is to share assessment information (i.e., test scores, observational data, interviews, work samples, review of records) and to integrate this information to develop an understanding of (a) the child's strengths and weaknesses and $(b)$ the factors in his/her environment that influence the problem behavior.

Step 3: Brainstorm alternative solutions. Once the ecology of the problem is understood, the team is ready to begin developing potential solutions. Four rules of brainstorming should, whenever possible, be followed to generate high-quality solutions. First, team members should try to generate as many ideas for solutions as possible. Second, team members should be encouraged to think creatively. Third, value judgments of alternatives should be withheld until the next stage of problem solving (i.e., step 4). Finally, the various alternatives should be examined with the purpose of combining and modifying them to create even more possible solutions.

Step 4: Choose among the alternatives. At this point in the process, it is the team's task to review critically the alternative solutions generated during brainstorming. Important questions to keep in mind when evaluating alternative solutions include: (a) How will the proposed solution affect the nonproblematic aspects of the child and classroom environment? $(b)$ Does the person who will implement the solution have the necessary skills and resources? If not, how will such deficiencies be handled? (c) Does the person who will implement the solution find it acceptable and perceive that it will be effective? After careful consideration of all alternatives, the team selects the solution or solutions that it believes will be most appropriate.

Step 5: Specify responsibilities and time lines. High-quality solutions are sometimes not implemented because of a failure to specify clearly each individual team member's responsibilities. This step of the process addresses the who, what, when, and where aspects of agreed-on solutions.

Step 6: Obtain consensus of team. At this point in the process, the team's leader should check with the members to ensure that there is a consensus regarding future actions to be initiated as a result of the meeting. If a lack of consensus exists, it may be necessary to go back to a prior step in the problem-solving process.

Step 7: Future actions on unaddressed problems. Given that many students have multiple problems, it is often necessary to focus on only a subset of them in any meeting due to behavioral priorities and practical time constraints. When this happens, the team should explicitly discuss the process of how other problems will be handled. If the team has an intervention plan to change a major problem of a student, it may want to postpone planning for dealing with other problems until it receives some feedback about the effectiveness of the first plan.

Step 8: Follow-up. This step occurs after the multidisciplinary team has concluded its meeting. It is essential that at least one team member provide short-term follow-up of the student to ensure that satisfactory progress is being made. This should occur 2-6 weeks after a plan has been implemented. Follow-up provides an opportunity for adjusting intervention plans and also provides team members with feedback about their decisions.

Characteristics of Effective Teams

Based on our review of research and experience in team meetings, we believe that 
at least seven characteristics maximize the effectiveness of teams. Each of these characteristics is discussed briefly below.

Group leadership. A leader plays a crucial role in managing the process of problem solving. Although leaderless groups are usually inefficient decision-making bodies, ideal results would often be obtained within an atmosphere of shared leadership. In shared leadership, each team member feels free to contribute to the team's process, in addition to sharing his or her content expertise, even though a single person is given the overall leadership responsibility for the group. One of the major leadership tasks is to ensure that the group follows problemsolving guidelines.

Planning activities. One characteristic of effective groups is that they do an adequate job of planning before the meeting begins. Pertinent information is thus distributed to team members prior to the meeting. Appropriate decisions are made regarding who should and should not attend the meeting.

Agenda setting. At the outset of the meeting, it is important for the group to establish an appropriate agenda. Among the relevant issues, the leader should help the group decide which topics they will address, the order of priority, and how much time will be devoted to each topic.

Clarifying communication. Clarity of verbal and nonverbal communication is essential if a team is to function effectively. Insuring clear communication is every team member's responsibility; however, the leader may enhance clarity and purpose in the meeting by using communication skills such as paraphrasing and summarization.

Participation of group members. One of the hallmarks of effective groups is the participation of all members. Each team member is, after all, on the team for a purpose. If some members dominate a team meeting at the expense of other members' participation, the team will have an inadequate range of professional perspectives during the problem-solving process. The parents of referred children are considered to be important members of the team, and every effort should be made to help them make a meaningful, active contribution to the team process.

Conflict management. Despite most people's discomfort with conflict, it is important not to stifle disagreements among team members. Differing perspectives are seen as a source of creative tension from which new and better ideas can emerge. Teams must distinguish between constructive and destructive conflict. The former is a positive event that adds to the quality of team decision making, while the latter results in inappropriate emotional arousal and irrational problem solving.

Review of group process. The process of each team meeting should be a legitimate point of discussion either during or at the conclusion of each session. The leader and members should accept and encourage relevant process contributions from team members even if they temporarily interrupt the flow of content information. Similarly, a review of process strengths and weaknesses following each team meeting is a good way to sharpen the process skills of team members and improve future meetings.

\section{Summary and Conclusion}

This article has focused on problem-solving activities of adults who, in turn, can affect the functioning of children at school and home. Consultation has become one of the preferred methods of delivering an array of special services to teachers and parents. Consultation is a cooperative, communicative activity that involves assessment and intervention knowledge and usually occurs over the course of several weeks. Evidence has been amassed to support the case for increased use of consultation; however, major impediments in the form of time commitments and a traditional service delivery structure in some schools remain as challenges to consultation. 
The problem-solving knowledge base underlying consultation was expanded on to build communication guidelines for educational conferences. The goals for such conferences are often numerous and complex; thus a system or guidelines for communicating assessment and intervention information among four or five adults is critical to the coordinated delivery of educational services for a given child. In addition to communication guidelines, the dynamics of group leadership and participation were discussed and suggestions for effective team meetings were offered.

Currently, a wide array of fundamental questions about consultation and conferencing exists and would benefit from more directed inquiry (i.e., research). One of the central tenets of consultation assumes that consultees (i.e., teachers and parents) acquire new skills from consultants and later apply these skills with other children. In other words, it is assumed that consultation is helpful to an original target child and will be preventive for children who may later experience similar problems. The preventive effects of consultation have yet to be adequately proven. Thus, the generalization to other children of actions resulting from consultation deserves researchers' at- tention. Embedded in this question of generalization is the basic issue of the consultee's retention of knowledge and skills that result from working with a consultant.

The issues of time and participant involvement appear to be the two most critical variables in successful conferencing. Research is needed that describes the different preconference activities of "successful" and "unsuccessful" conferences. In addition, interview and group structuring tactics that facilitate participation from all persons in a conference need to be better understood. Finally, models for training educators to lead child conference teams need to be experimentally tested and compared to determine effective training approaches.

In this article, we have discussed mostly practical information about ways that adults who are interested in helping children can more effectively communicate and work together. These practical suggestions are based on some research and on our own educational experiences. More research, however, is needed to document effective means of serving children. The topics of consultation and school-based teams should be high priorities for future researchers interested in facilitating the mainstreaming of children.

\section{Appendix A}

\section{Sample Prereferral Behavior Inventory and Intervention Planner for Assessing Effective Teaching Behaviors}

Teachers play a critical role in facilitating students' academic and social development. Therefore, understanding a teacher's behavior and his/her classroom is often essential to developing a plan for improving a referred student's performance. Please complete the following sections on classroom management and resources accurately.

Frequency of Performance

My Classroom Management and Instructional Behaviors

Almost Never Often

Almost Always

1. I provide prompts and reminders of task procedures before students are expected to carry them out.

2. I clearly state classroom rules.

3. I require participation of all students.

4. I establish and follow a classroom routine and procedures.

5. I provide systematic feedback on student performances. 
Frequency of Performance

My Classroom Management and Instructional Behaviors

Almost Never Often Almost Always

6. I clearly explain consequences for appropriate and inappropriate behavior.

7. I use negative or failure experiences to teach more appropriate ways of functioning.

8. I clearly state my expectations for student behavior or performance.

9. I schedule time for students to review work.

10. I circulate through the room and observe student work behavior.

11. I hold students accountable for timely completion of required work.

12. I follow through with stated consequences quickly and consistently.

13. I request and use student input about classroom procedures and rules.

14. I focus on what students should be doing, not on what they should not be doing.

15. I have students practice a new rule or procedures.

16. I post important classroom rules or procedures so all students can see them.

$\begin{array}{lll}1 & 2 & 3 \\ 1 & 2 & 3 \\ 1 & 2 & 3 \\ 1 & 2 & 3 \\ 1 & 2 & 3 \\ 1 & 2 & 3 \\ 1 & 2 & 3 \\ 1 & 2 & 3 \\ 1 & 2 & 3 \\ 1 & 2 & 3 \\ 1 & 2 & 3\end{array}$

\section{Appendix B}

\section{Sample Items from the Prereferral Behavior Inventory and Intervention Planner for Assessing Acceptability of Classroom Interventions}

Regular Classroom Interventions

Teachers have a rather extensive repertoire of techniques for changing students' academic and social behavior. Below is a list of 34 possible techniques that could be used to change the target student's behavior. Please read each brief description of a technique and then rate $(a)$ how much you like the technique, $(b)$ how easy it is to use in your class, and $(c)$ how effective you think the technique would be with the target student.

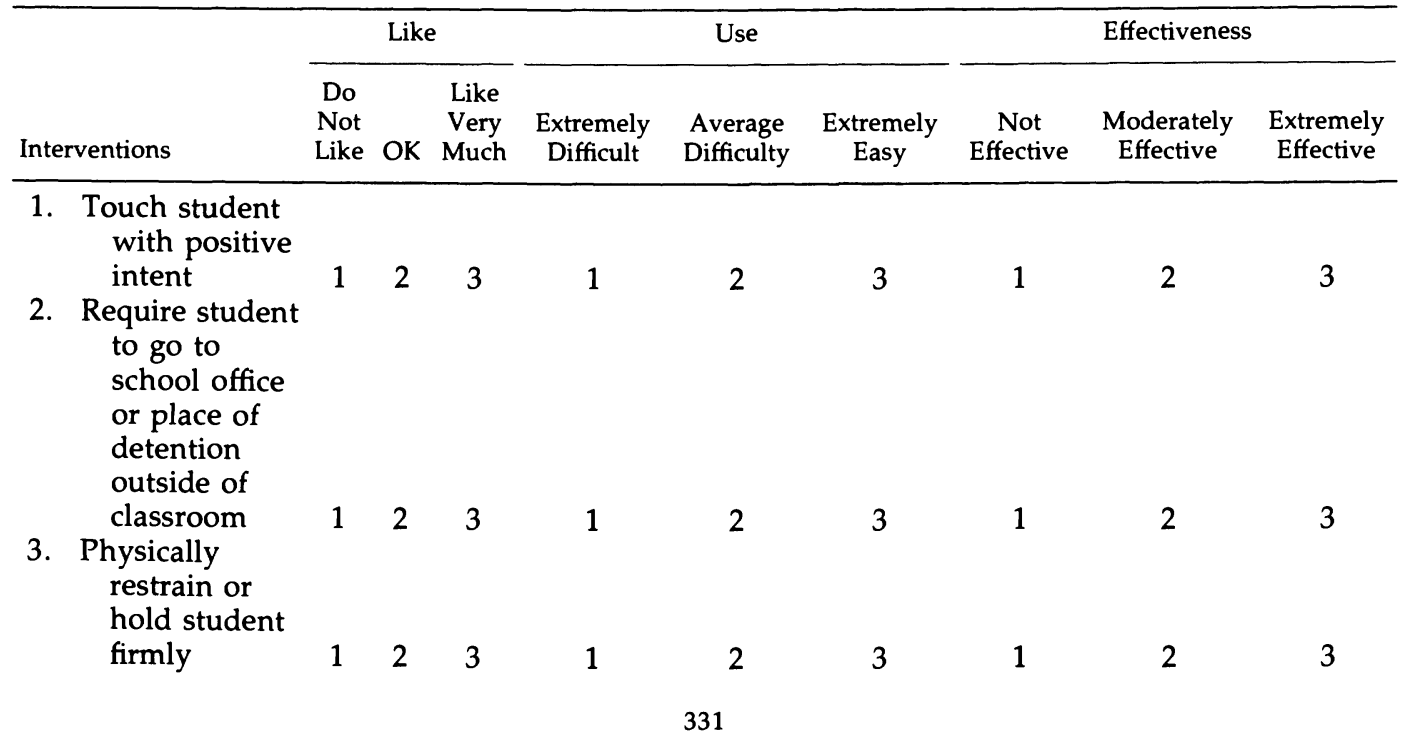




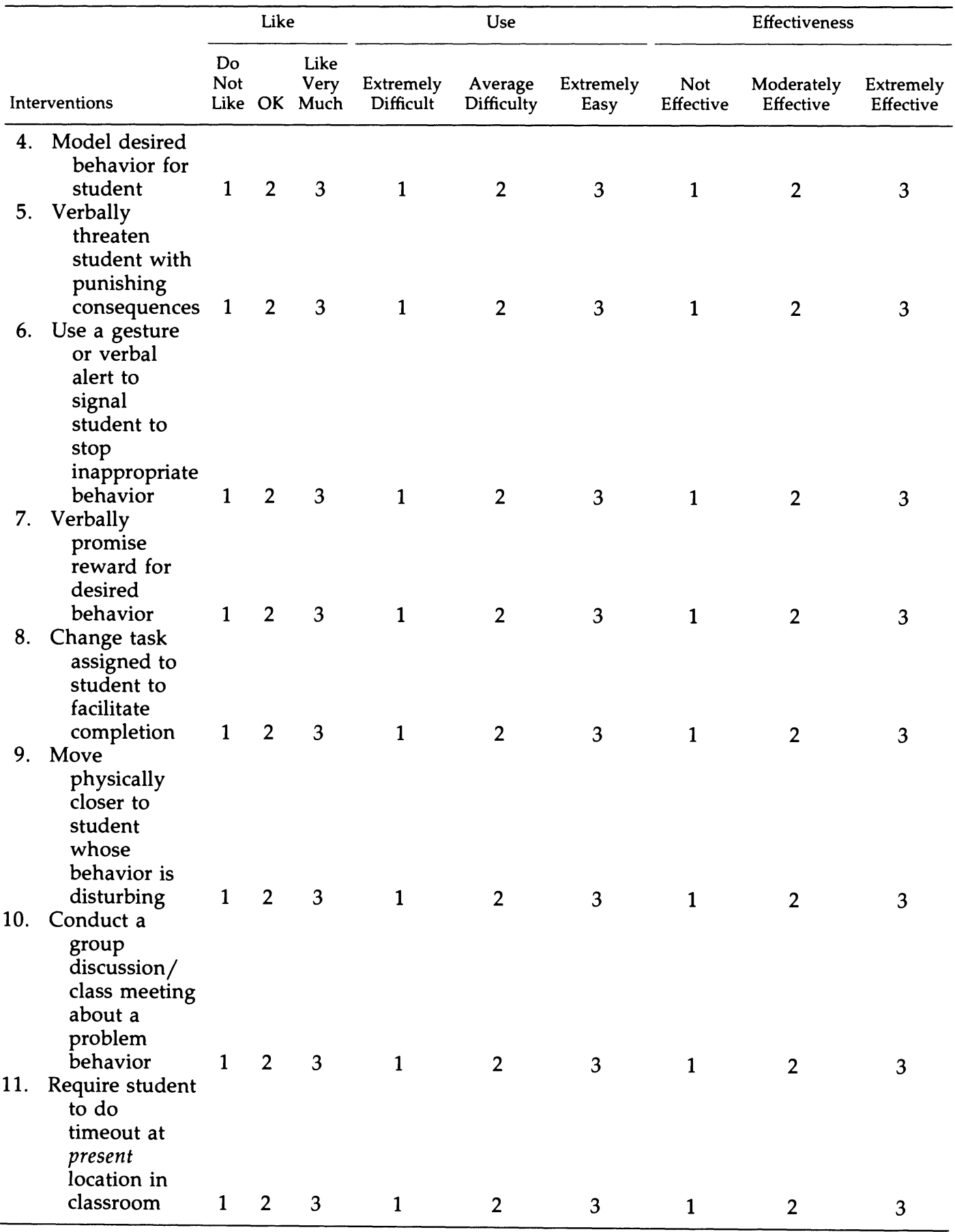




\section{Behavior Intervention Rating Scale}

Please evaluate the intervention by circling the number that best describes your agreement or disagreement with each statement.

\begin{tabular}{llllll}
\hline & Stongly & Slightly & Slightly & & Strongly \\
Disagree & Disagree & Disagree & Agree & Agree & \begin{tabular}{c} 
Agree \\
\hline
\end{tabular} \\
\hline
\end{tabular}

1. This was an acceptable

intervention for the child's

problem behavior.

1

2

3

4

5

6

2. Most teachers would find this

intervention appropriate

for behavior problems in addition to the one

identified.

1

2

3

4

5

6

3. The intervention proved effective in changing the child's problem behavior.

4. I would suggest the use of this intervention to other teachers.

1

2

3

4

5

6

1

2

3

4

5

6

5. The child's behavior problem was severe enough to warrant use of this intervention.

1

2

3

4

6

6. Most teachers would find this intervention suitable for the behavior problem described.

7. I am willing to use this intervention again in the classroom setting.

8. The intervention did not result in negative side effects for the child.

9. The intervention is

appropriate for a variety of children.

10. The intervention is consistent with those I have used in classroom settings.

11. The intervention was a fair way to handle the child's problem behavior.

1

2

3

4

6

1

2

3

4

6

1

2

3

4

6

1

2

3

4

6

1

2

3

4

6

1

2

3

4

6

12. The intervention is reasonable for the behavior problem identified.

13. I like the procedures used in the intervention.

14. The intervention was a good way to handle this child's behavior problem.

15. Overall, the intervention was beneficial for the child.

16. The intervention quickly improved the child's behavior. 


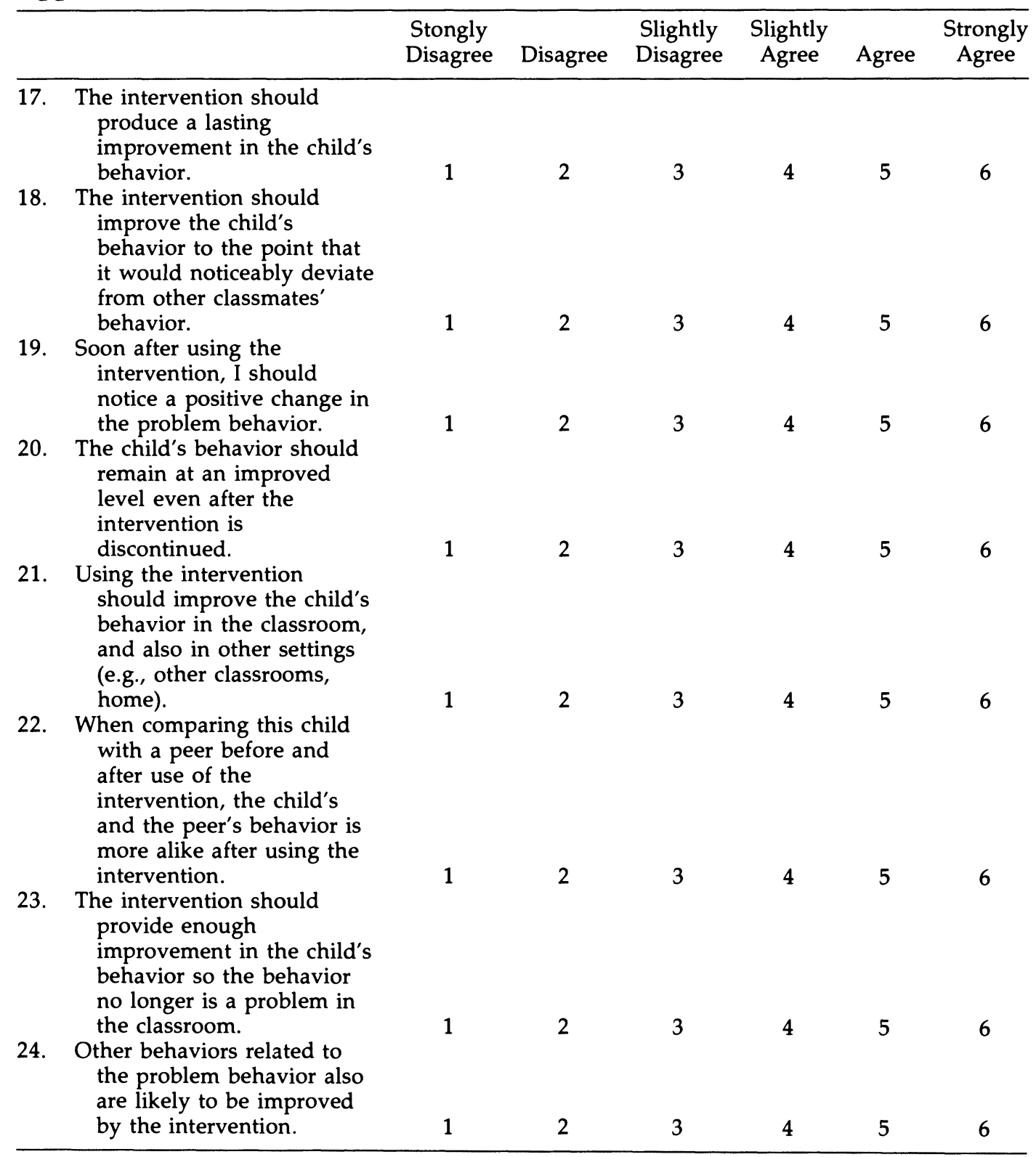

\section{Appendix D \\ Guidelines for Team Problem Solving}

1. Define and clarify the presenting problem.
A. State the problem in explicit, concrete terms. Avoid being vague.
B. When appropriate, divide the problem into component parts.
C. Prioritize component parts.
D. Specifiy which components will be ad- dressed by the team.
E. Determine goals for appropriate compo- nent parts specified in prior stage.

2. Analyze the context of the problem.
A. Identify factors contributing to the prob- lem or impeding its solution.
B. Identify factors and resources that may contribute to the problem's solution.


C. Identify other factors that should be taken into account (e.g., administrative policies, programmative limitations, etc.).

3. Brainstorm multiple alternative solutions for the problem.

4. Choose among the alternatives.

5. Specify responsibilities and time lines.

6. Obtain consensus regarding the adequacy of proposed actions. Recycle to prior steps if necessary.

7. Discuss future course of action for component parts of problem not discussed by team.

8. Follow up.

\section{Appendix E \\ Questions to Assist Implementation of Guidelines for Team Problem \\ Solving*}

Questions related to planning:

What are our chief concerns for this group of students?

What information do we need in order to understand our concerns more fully and plan interventions to address them?

How should we go about obtaining this information?

Who will take responsibility for gathering the information and organizing it?

When will we meet to evaluate the information we have and plan what needs to be done next?

Questions related to curriculum implementation:

Do the students have needs that are not being met by the present programs?

What program changes are feasible?

How do these changes fit in with overall curriculum planning for the school? For the school system?

What resources, both personal and material, are required to implement them?

Questions related to evaluation:

Has the program been successful?

How do we know?

What could we do better next time?

* From Siegel and Cole (1990b, p. 204), reproduced with the permission of Hogfere \& Huber Publishers, 12 Bruce Park Avenue, Toronto, Ontario M4P 253, from Effective Consultation in School Psychology, edited by E. Cole and J. A. Siegel, 1990. Copyright (C) 1990 by Hogrefe \& Huber.

\section{References}

Algozzine, B., \& Ysseldyke, J. E. (1981). Special education services for normal children: Better safe than sorry. Exceptional Children, 48, 238243.

Alpert, J., \& Trachtman, G. (1980). School psychological consultation in the eighties: Relevance for the delivery of social services. School Psychology Review, 9, 234-238.

Alpert, J., \& Yammer, M. D. (1983). Research in school consultation: A content analysis of selected journals. Professional Psychology: Research and Practice, 14, 604-612.

American Association of School Administrators (AASA). (1988). Challenges for school leaders. Arlington, VA: Author.

Anserello, C., \& Sweet, T. (1990). Integrating consultation into school psychological services. In E. Cole \& J. A. Siegel (Eds.), Effective consultation in school psychology (pp. 173200). Lewiston, NY: Hogrefe \& Huber.

Applied Management Sciences. (1979). Study for determining the least restrictive environment (LRE) placement for handicapped children. Final Report to Bureau of Educationally Handicapped.

Armer, B., \& Thomas, B. K. (1978). Attitudes towards interdisciplinary collaboration in pupil personnel service teams. Journal of School Psychology, 16, 168-177.

Bergan, J. (1977). Behavioral consultation. Columbus, OH: Merrill.

Bergan, J. R., \& Kratochwill, T. R. (1990). Behavioral consultation in applied settings. New York: Plenum.

Bergan, J., \& Neumann, A. (1980). The identification of resources and constraints influencing plan design in consultation. Journal of School Psychology, 18, 317-323.

Bergan, J., \& Tombari, M. (1975). The analysis of verbal interactions occurring during consultation. Journal of School Psychology, 13, 209-226.

Bergan, J., \& Tombari, M. (1976). Consultant skill and efficiency and the implementation and outcome of consultation. Journal of School Psychology, 14, 3-14.

Black, B. J. (1977). The teams gallop through the catchment areas. Accepted and Community Psychology, 28, 917-918.

Butler, A. S., \& Maher, C. A. (1981). Conflict and special service teams: Perspectives and suggestions for school psychologists. Journal of School Psychology, 19, 62-70.

Carnegie Task Force on Teaching as a Profession. (1986). A nation prepared: Teachers for the 21st century. New York: Carnegie Forum on Education and the Economy.

Christenson, S., Ysseldyke, J. E., \& Algozzine, B. (1982). Institutional constraints and external pressures influencing referral decisions. Psychology in the Schools, 19, 341-345. 
Cole, E., \& Siegel, J. A. (Eds.). (1990). Effective consultation in school psychology. Lewiston, NY: Hogrefe \& Huber.

Conoley, J. C. (Ed.). (1986). Mini-series on indirect service delivery. School Psychology Review, 15(4), 455-545.

Conoley, J. C., \& Conoley, C. W. (1982). School consultation: A guide to practice and training. Elmsford, NY: Pergamon.

Curtis, M. J., \& Meyers, J. (1988). Consultation: A foundation for alternative services in the schools. In J. L. Graden, J. E. Zins, \& M. J. Curtis (Eds.), Alternative educational delivery systems: Enhancing instructional options for all students (pp. 35-48). Washington, DC: National Association of School Psychologists.

Curtis, M. J., \& Zins, J. E. (1988). Effects of training in consultation and instructor feedback on acquisition of consultation skills. Journal of School Psychology, 26, 185-190.

Dunst, C. J., \& Trivette, C. M. (1988). Helping, helplessness, and harm. In J. C. Witt, S. N. Elliott, \& F. M. Gresham (Eds.), The handbook of behavior therapy in education (pp. 343376). New York: Plenum.

Elliott, S. N. (1986). Training multidisciplinary team members in problem solving and leadership skills. A workshop for Wisconsin School Psychologists, Wisconsin Dells, WI.

Elliott, S. N. (1988). Acceptability of behavioral treatments in educational settings. In J. C. Witt, S. N. Elliott, \& F. M. Gresham (Eds.), The handbook of behavior therapy in education (pp. 121-150). New York: Plenum.

Elliott, S. N., \& Gresham, F. M. (1989). The Prereferral Behavior Inventory and Intervention Planner. Unpublished test. Madison: University of Wisconsin.

Fenton, K. S., Yoshida, R. K., Maxwell, J. P., \& Kaufman, M. J. (1979). Recognition of team goals: An essential step toward rational decision making. Exceptional Children, 45, 638644.

Friend, M., \& Cook, L. (1990). Collaboration as a predictor for success in school reform. Journal of Educational and Psychological Consultation, 1, 69-86.

Fuchs, D., \& Fuchs, L. S. (1989). Exploring effective and efficient prereferral interventions: A component analysis of behavioral consultation. School Psychology Review, 18, 260283.

Goldstein, S., Strickland, B., Turnbull, A. P., \& Curry, L. (1980). An observational analysis of the IEP conference. Exceptional Children, 46, 278-286.

Graden, J. L., Casey, A., \& Christenson, S. L. (1985). Implementing a prereferral interven- tion system. Part I: The model. Exceptional Children, 51, 377-384.

Gresham, F. M. (1984). Behavioral interviews in school psychology: Issues in psychometric adequacy and research. School Psychology Review, 13, 17-25.

Gresham, F. M., \& Kendell, G. K. (1987). School consultation research: Methodological critique and future research directions. School Psychology Review, 16, 306-316.

Gutkin, T. B. (1980). Teacher perceptions of consultation services provided by school psychologists. Professional Psychology, 11, 637642.

Gutkin, T. B. (1986). Consultees' perceptions of variables relating to the outcomes of schoolbased consultation interactions. School Psychology Review, 15, 375-382.

Gutkin, T. B., \& Bossard, M. D. (1984). The impact of consultant, consultee, and organizational variables on teacher attitudes toward consultation services. Journal of School Psychology, 22, 251-258.

Gutkin, T. B., \& Curtis, M. (1982). School-based consultation: Theory and techniques. In C. R. Reynolds \& T. B. Gutkin (Eds.), The handbook of school psychology (pp. 796-828). New York: Wiley.

Gutkin, T. B., \& Curtis, M. J. (1990). Schoolbased consultation: Theory, techniques, and research. In T. B. Gutkin \& C. R. Reynolds (Eds.), The handbook of school psychology (2d ed., pp. 577-611). New York: Wiley.

Gutkin, T. B., Henning-Stout, M., \& Piersel, W. C. (1988). Impact of a district-wide behavioral consultation prereferral intervention service on patterns of school psychological service delivery. Professional School Psychology, 3, 301-308.

Gutkin, T. B., Singer, J., \& Brown, R. (1980). Teacher reactions to school-based consultation services: A multivariate analysis. Journal of School Psychology, 18, 126-134.

Happe, D. (1982). Behavioral intervention: It doesn't do any good in your briefcase. In J. Grimes (Ed.), Psychological approaches to problems of children and adolescents (pp. 1541). Des Moines: Iowa Department of Public Instruction.

Haring, N. G. (1988). A technology for generalization. In N. G. Haring (Ed.), Generalization for students with severe handicaps: Strategies and solutions (pp. 5-11). Seattle: University of Washington Press.

Hefferin, E. A., \& Katz, A. H. (1971). Issues and orientations in the evaluation of rehabilitation programs. Rehabilitation Literature, 32, 66-73. 
Holmes Group. (1986). Tomorrow's teachers. East Lansing, MI: Author.

Huebner, E. S., \& Hahn, B. M. (1990). Best practices in coordinating multidisciplinary teams. In A. Thomas \& J. Grimes (Eds.), Best practices in school psychology-II (pp. 235-246). Washington, DC: National Association of School Psychologists.

Idol, L., Paolucci-Whitcomb, P., \& Nevin, A. (1986). Collaborative consultation. Rockville, MD: Aspen.

Idol, L., \& West, J. F. (1987). Consultation in special education: Part II. Training and practice. Journal of Learning Disabilities, 20, 474-494.

Jackson, R. M., Cleveland, J. C., \& Merenda, P. F. (1975). The longitudinal effects of early identification and counseling of underachievers. Journal of School Psychology, 13, 119-128.

Kazdin, A. E. (1981). Acceptability of child treatment techniques: The influence of treatment efficacy and adverse side effects. Behavior Therapy, 12, 493-506.

Knitzer, J. (1982). Mental health services to children and adolescents: A national view of public policies. American Psychologist, 39, 905-911.

Kratochwill, T. R., \& Bergan, J. R. (1990). Behavioral consultation in applied settings. New York: Plenum.

Kratochwill, T. R., Elliott, S. N., \& Rotto, P. (1990). Behavioral consultation in school psychology. In A. Thomas \& J. Grimes (Eds.), Best practices in school psychology-II (pp. 147-170). Washington, DC: National Association of School Psychologists.

Maher, C. A., \& Yoshida, R. K. (1985). Multidisciplinary teams in the schools: Current status and future possibilities. In T. R. Kratochwill (Ed.), Advances in school psychology (Vol. 4, pp. 13-44). Hillsdale, NJ: Erlbaum.

Medway, F. J. (1979). How effective is school consultation? A review of recent research. Journal of School Psychology, 17, 275-282.

Medway, F. J. (1982). School consultation research: Past trends and future directions. Professional Psychology, 13, 422-430.

Meyers, V., Liddell, A., \& Lyons, M. (1977). Behavioral interviews. In A. R. Ciminero, K. S. Calhoun, \& H. E. Adams (Eds.), Handbook of behavioral assessment (pp. 117-152). New York: Wiley.

Meyers, J., Parsons, R. D., \& Martin, R. P. (1979). Mental health consultation in the schools. San Francisco: Jossey-Bass.

National Commission on Excellence in Education. (1983). A nation at risk: The imperative for educational reform. Washington, DC: U.S. Government Printing Office.
Nevin, A., Thousand, J., Paolucci-Whitcomb, P., \& Villa, R. (1990). Collaborative consultation: Empowering public school personnel to provide heterogeneous schooling for all-or, who rang that bell? Journal of Educational and Psychological Consultation, 1, 41-68.

Pfeiffer, S. I. (1980). The school-based interprofessional team: Recurring problems and some possible solutions. Journal of School Psychology, 18, 388-394.

Pfeiffer, S. I. (1981). The problems facing multidisciplinary teams: As perceived by team members. Psychology in the Schools, 18, 330333.

Pfeiffer, S. I., \& Hefferman, L. (1984). Improving multidisciplinary team functions. In C. A. Maher, R. J. Illback, \& J. E. Zins (Eds.), Organizational psychology in the schools: $A$ handbook for professionals (pp. 283-301). Springfield, IL: Charles C. Thomas.

Pfeiffer, S. I., \& Naglieri, J. (1983). An investigation of multidisciplinary team decisionmaking. Journal of Learning Disabilities, 16, 588-590.

Phillips, V., \& McCullough, L. (1990). Consultation-based programming: Instituting the collaborative ethic in schools. Exceptional Children, 56, 291-304.

Poland, S., Ysseldyke, J., Thurlow, M., \& Mirkin, P. (1979). Current assessment and decisionmaking practices in school settings as reported by directors of special education (Research Report No. 14). Minneapolis: University of Minnesota, Institute for Research on Learning Disabilities.

Ritter, D. R. (1978). Effects of a school consultation program upon referral patterns of teachers. Psychology in the Schools, 15, 239243.

Saxe, L., Cross, T., \& Silverman, N. (1988). Children's mental health: The gap between what we know and what we do. American Psychologist, 43, 800-807.

Schmuck, R. A. (1990). Organization development in schools: Contemporary concepts and practices. In T. B. Gutkin \& C. R. Reynolds (Eds.), The handbook of school psychology (2d ed., pp. 901-921). New York: Wiley.

Schmuck, R. A., \& Runkel, P. J. (1972). Organizational training. In R. A. Schmuck (Ed.), Handbook of organizational development in schools (pp. 275-301). Palo Alto, CA: Mayfield.

Sheridan, S. M., Kratochwill, T. R., \& Elliott, S. N. (1990). Behavioral consultation with parents and teachers: Delivering treatment for socially withdrawn children at home and school. School Psychology Review, 19, 75-94. 
Siegel, J. A., \& Cole, E. (1990a). Appraisal for better curriculum. In E. Cole \& J. A. Siegel (Eds.), Effective consultation in school psychology (pp. 201-245). Lewiston, NY: Hogrefe \& Huber.

Siegel, J. A., \& Cole, E. (1990b). Role expansion for school psychologists: Challenges and future directions. In E. Cole \& J. A. Siegel (Eds.), Effective consultation in school psychology (pp. 3-17). Lewiston, NY: Hogrefe \& Huber.

Smith, C. R., \& Knoff, H. M. (1981). School psychology and special education students' placement decisions: IQ still tips the scale. Journal of Special Education, 15, 55-64.

Updyke, J. F., Melton, E. C., \& Medway, F. (1981). The effectiveness of school consultation: A meta-analysis perspective. Paper presented at the meeting of the National Association of School Psychologists, Houston, TX.

Von Brock, M. B., \& Elliott, S. N. (1985). The influence of treatment effectiveness information on the acceptability of classroom interventions. Journal of School Psychology, 25, 131-144.

Wallace, G. (1976). Interdisciplinary efforts in learning disabilities: Issues and recommendations. Journal of Learning Disabilities, 9, 5965.

Witt, J. C., \& Elliott, S. N. (1983). Assessment in behavioral consultation: The initial interview. School Psychology Review, 12, 42-49.

Witt, J. C., \& Elliott, S. N. (1985). Acceptability of classroom intervention strategies. In T. R. Kratochwill (Ed.), Advances in school psychology (Vol. 4, pp. 251-288). Hillsdale, NJ: Erlbaum.
Witt, J. C., \& Martens, B. K. (1988). Problems with problem-solving consultation: A reanalysis of assumptions, methods, and goals. School Psychology Review, 17, 211-226.

Witt, J. C., Moe, G., Gutkin, T., \& Andrews, L. (1984). The effect of saying the same thing in different ways: The problem of language and jargon in school-based consultation. Journal of School Psychology, 22, 361-367.

Yoshida, R. K. (1980). Multidisciplinary decision making in special education: A review of issues. School Psychology Review, 9, 221-227.

Ysseldyke, J. E. (1983). Current practices in making psychoeducational decisions about learning disabled students. Journal of Learning Disabilities, 16, 226-233.

Ysseldyke, J. E., Algozzine, R., \& Thurlow, M. (1980). A naturalistic investigation of special education team meetings (Research Report No. 40). Minneapolis: University of Minnesota, Institute for Research on Learning Disabilities.

Ysseldyke, J. E., Regan, R. R., \& Schwartz, J. (1980). The use of technically adequate tests in psychoeducational decision making (Research Report No. 28). Minneapolis: University of Minnesota, Institute for Research on Learning Disabilities.

Zins, J. E., Curtis, M. J., Graden, J. L., \& Ponti, C. R. (1988). Helping students succeed in the regular classroom. San Francisco: Jossey-Bass.

Zins, J. E., \& Ponti, C. R. (1990). Best practices in school-based consultation. In A. Thomas \& J. Grimes (Eds.), Best practices in school psychology-II (pp. 673-694). Washington, DC: National Association of School Psychologists. 